\title{
Representações sociais de leitura: o texto literário em sua função lúdica e educativa
}

\author{
Geisa Magela Veloso' (D) \\ Aparecida Paiva"l (D)
}

RESUMO

O artigo tem por objetivo discutir processos de ancoragem e objetivação das representações sociais de leitura literária produzidos por professoras da rede pública de ensino. Foi realizada pesquisa qualitativa, em que participaram 94 professoras dos anos iniciais do Ensino Fundamental. A análise dos dados está referenciada na teoria das representações sociais proposta por Moscovici $(1978,2015)$, que entende o processo representacional como forma de conhecimento que tem por função a elaboração de comportamentos e a comunicação. Constatou-se que as professoras ancoram a leitura literária na ludicidade do texto e na possibilidade de utilizá-lo para ensinar e educar as crianças. Dado que o prazer não se constitua como objetivo da escola, as professoras fazem adesão às práticas de dramatização para conferir concretude e materialidade ao prazer de ler.

\section{PALAVRAS-CHAVE}

representações sociais; leitura literária; ludicidade; literatura infantil. 


\title{
SOCIAL REPRESENTATIONS OF READING: LUDIC AND EDUCATIONAL FUNCTIONS OF LITERARY TEXT
}

\begin{abstract}
The article aims to discuss processes of anchoring and objectifying the social representations of literary reading produced by public school teachers. Ninety four (94) teachers from the early years of elementary school participated in this qualitative research. The data analysis is referenced in the theory of social representations proposed by Moscovici $(1978,2015)$, who understands the representational process as a form of knowledge which functions as the elaborator of behaviors and communication. It was found that the teachers anchor literary reading in the playfulness of the text and in the possibility of using it to teach and educate children. Since pleasure is not the school's objective, teachers adhere to dramatization practices to give concreteness and materiality to the pleasure of reading.

KEYWORDS

social representations; literary reading; playfulness; children's literature.
\end{abstract}

\section{REPRESENTACIONES SOCIALES DE LECTURA: EL TEXTO LITERARIO EN SU FUNCIÓN LÚDICA Y EDUCATIVA}

\section{RESUMEN}

El artículo discute los procesos de anclaje y objetivación de las representaciones sociales de la lectura literaria producida por maestros de escuelas públicas. Se realizó una investigación cualitativa, en el que participaron 94 docentes de la escuela primaria. El análisis está referenciado en las representaciones sociales propuesta por Moscovici (1978, 2015), como forma de conocimiento cuya función es la elaboración de comportamientos y comunicación. Se descubrió que los maestros anclan la lectura literaria en lo placer del texto y en la posibilidad de usarlo para enseñar y educar a los niños. Dado que el placer no es el objetivo de la escuela, los maestros se adhieren a las prácticas de dramatización para dar concreción y materialidad al placer de la lectura.

PALABRAS CLAVE

representaciones sociales; lectura literaria; lúdico; literatura infantil. 


\section{INTRODUÇÃO}

A pesquisa situou-se no campo de estudos da leitura, por considerar que este é um espaço onde emergem inquietações que impõem a necessidade de se compreender a condição daquele que se apropriou das habilidades de ler e escrever. O estudo teve por objetivo discutir processos de ancoragem e objetivação das representações sociais de leitura literária produzidos por professoras da rede pública de ensino. Pela investigação das representações de leitura procuramos compreender o contexto social em que estas foram produzidas, os mecanismos engendrados para sua produção, bem como as implicações nos processos didáticos de escolarização do texto literário e nas práticas de letramento desenvolvidas nos anos iniciais do Ensino Fundamental.

A pesquisa teve como interlocutores um conjunto composto por 94 professoras ${ }^{1}$ do Ensino Fundamental I, atuantes em escolas municipais de Montes Claros. No universo tomado como referência, elegemos como sujeitos aqueles que participaram da disciplina Literatura Infantil, ofertada no âmbito do Curso Normal Superior, desenvolvido pela Universidade Estadual de Montes Claros (Unimontes). Essas professoras foram importantes parceiras, fornecerem elementos essenciais necessários ao levantamento de suas representações de leitura literária, bem como a análise e compreensão das práticas de leitura efetivadas.

Como ferramenta metodológica para a coleta de dados foi aplicado um questionário composto por questões abertas, em que as professoras puderem manifestar livremente suas concepções e crenças, valores, experiências, vivências e práticas. O planejamento e execução da atividade, e o tratamento e organização de dados se orientaram com rigor e intencionalidade, como forma de garantir a consecução do objetivo pretendido. A opção metodológica tornou possível compreender as significações produzidas pelos sujeitos, manifestas em seus discursos e em suas ações cotidianas. A escolha fundamentou-se no conhecimento produzido em relação às pesquisas qualitativas e às investigações de Representações Sociais, que nos apontam direções a partir de uma vasta literatura.

Consideramos com Bogdan e Bicklen (1994) que, ainda que a investigação qualitativa no campo da educação se constitua como abordagem com longa e rica tradição, a conquista de seu reconhecimento se operou, sobretudo, nas últimas décadas do século XX. Importante destacar a primazia da compreensão como princípio fundante da produção de conhecimento, por processo em que se estudam relações complexas, sem a pretensão de explicá-las por meio do isolamento de variáveis, dado que a pesquisa qualitativa se constitua como ato subjetivo de construção.

De modo semelhante pode-se dizer que, em relação às Representações Sociais, as últimas décadas presenciaram grande expansão dos estudos, discussões

1 Neste artigo optamos por utilizar o genérico feminino - professora/professoras para fazer referência aos participantes do estudo. Apesar de reconhecermos que tem crescido o número de homens no corpo docente da Educação Infantil e do Ensino Fundamental I, este ainda se mantém majoritariamente feminino, numa proporção que representa mais de $95 \%$ de mulheres. 
e percursos metodológicos. Consideramos as representações sociais como fenômenos complexos, dinâmicos e heterogêneos, cujo campo de estudos encontra-se alicerçado na definição conceitual proposta por Moscovivi, que ganhou visibilidade com o livro La psychanalyse: son image et son public, publicado em 1961. Moscovici (1978) formulou o conceito de representações sociais na direção das representações coletivas postuladas pelo sociólogo francês Emile Durkheim. Com a utilização da expressão representação coletiva, Durkheim quis designar a especificidade do pensamento social em relação ao pensamento individual. Na lógica das proposições de Durkheim, a representação coletiva não se reduz à soma das representações dos indivíduos e constitui-se como um primado do social sobre o individual, a superação deste por aquele (Moscovici, 1978).

Para Moscovici (2015), as representações sociais se constituem como sistema de valores, ideias e práticas, construções individuais engendradas coletivamente, uma via de apreensão do mundo concreto que se apresenta com uma dupla função. De um lado, as representações sociais têm a função de estabelecer uma ordem, que orienta as pessoas em seu mundo material e social, além de permitir controlá-lo. De outro lado, fornecem um código para nomear e classificar os vários aspectos de seu mundo e da sua história individual e social, visando que a comunicação seja possível entre os membros de uma comunidade (Moscovici, 2015). Em outras palavras, representações sociais são uma modalidade de conhecimento particular que visa à elaboração de comportamentos e a comunicação entre os indivíduos (Moscovici, 1978). "Ao serem internalizadas, as representações passam a expressar as relações do sujeito com o mundo que ele conhece, e ao mesmo tempo, elas o situam nesse mundo" (Duveen, 1995, p. 267).

As representações sociais são formas de conhecimento individual, que se compõem por figuras e expressões socializadas, acerca de um fenômeno socialmente valorizado. Constituem-se como conhecimento socialmente elaborado porque, embora sejam produzidas a partir de experiências pessoais, servem-se de informações, crenças, valores, modelos, expectativas, práticas vivenciadas através de processos educativos e da tradição cultural dos grupos sociais. "As representações sociais decorrem do processo de socialização e estão diretamente associadas à identidade coletiva" (Daniel, Antunes e Amaral, 2015, p. 291).

As Representações Sociais sobre um dado fenômeno não se constituem como mero agregado de significações individuais, por isso a sua análise deve centrar-se nos processos de mediação social que as engendraram e lhes conferem uma estrutura peculiar. As representações são individuais, uma vez que são construídas pelos sujeitos pela via dos processos de comunicação e mediação social. E são sociais justamente porque não se referem a indivíduos isolados, mas a sujeitos em interação.

É assim que a investigação de representações sociais ultrapassa o levantamento de construções individuais, para realizar um mapeamento do sistema de significação produzido pelos sujeitos, buscando-se apreender as mediações pelas quais estes signos e sentidos se constituíram. Esta é uma atividade atravessada pela subjetividade dos processos construtivos dos sujeitos e realiza um levantamento da inteligibilidade socialmente produzida em determinada época ou por determinado agrupamento humano. 
Em nosso estudo, os discursos emitidos pelas professoras são, portanto, um espaço fundamental para a compreensão das práticas de leitura mediadas, como também dos conteúdos culturais em circulação, dos desejos e expectativas, sonhos, utopias e esperanças que estes sujeitos nutrem em relação à leitura literária. As representações elaboradas pelas professoras definem o mundo e lhes garantem o seu lugar nele, constituindo a sua identidade e o seu pertencimento.

Por esse sentido, em nosso estudo, para compreender as representações de leitura literária das professoras do Ensino Fundamental I, procuramos ultrapassar a identificação de significações individuais, para entender o modo social de sua constituição. Afinal, a atividade representacional é mediada pelos processos sociais, sendo que as professoras se inserem em um contexto, influenciando-o e dele sofrendo influências. Para captar essas influências, o estudo privilegiou os processos de comunicação mediados pela linguagem. Minayo (1995) considera que, apesar de traduzir um pensamento fragmentário e muitas vezes contraditório, a linguagem é a mediação privilegiada para o estudo das Representações Sociais, que se manifestam em palavras, sentimentos e condutas, podendo ser analisadas a partir da compreensão das estruturas e dos comportamentos sociais.

Comunicação e linguagem são fenômenos baseados em vários tipos de tensão entre falantes e ouvintes que são essenciais para o conceito de representações sociais. Representações são formadas, mantidas e mudadas na e por meio da linguagem e da comunicação e, da mesma forma, o uso de palavras e atributos ligados aos sentidos transforma as representações sociais. (Marková, 2017, p. 363)

As interações entre os grupos são heterogêneas e seus contextos específicos produzem uma variedade de estilos de pensamento e comunicação, alguns baseados em consenso, outros em dissenso e contradição (Marková, 2017). Em nosso estudo, constatamos uma grande variedade de conteúdos e práticas, em que as representações de leitura literária produzidas pelas professoras podem parecer conflituosas e confusas - pregam o prazer de ler, o desejo por livros, a liberdade de escolha e a fruição estética, quando suas práticas se encaminham para a funcionalidade do texto, para o ensino de conteúdos curriculares e, sobretudo, de valores morais. No entanto, consideramos que os discursos se ajustam à situação de interlocução, sem que isso indique uma "falta de autenticidade ou de atitude maquiavélica destinada a ocultar uma opinião 'verdadeira”' (Moscovici, 1978, p. 50). Para o autor, nessas situações, somente o processo usual de interação está em causa e controla o emprego da linguagem e dos códigos que melhor se ajustem à ocasião. Os sujeitos procuram aprovação ou esperam que suas respostas possam acarretar satisfação de ordem intelectual ou pessoal, havendo perfeita consciência de que, diante de outro interlocutor ou em outras circunstâncias, sua mensagem seria diferente. Importante destacar que os discursos não são neutros, mas, estão inseridos em estratégias e práticas de poder e associam-se aos interesses e necessidades de quem os produz.

Nessa perspectiva, as representações sociais podem se manifestar diferentemente nos discursos e nas ações, em um movimento aparentemente contraditório. 
No entanto, Becker (1993) afirma que, em pesquisa, constitui-se um erro considerar uma destas expressões como real e a outra como dissimulação. Para o autor, os valores de um grupo social são um ideal, para o qual o comportamento real pode se aproximar, mas raramente incorporar integralmente.

Os comportamentos manifestos pelos sujeitos se integram ao conteúdo de suas representações e, por isso, discursos e práticas não podem ser separados e ligados por uma relação de causa-efeito. Por essa lógica, em nosso estudo, consideramos que as representações das professoras se fazem presentes nos seus discursos, também sendo identificadas no processo de escolarização da literatura e nas práticas de leitura decorrentes. As práticas de leitura desenvolvidas pelas professoras não podem ser consideradas como consequência de suas representações, mas constituem-se como outra dimensão em que o seu conteúdo se manifesta.

Para compreender as representações das professoras, foi realizada uma investigação que privilegiou os sentidos produzidos e a interpretação desse sistema de significação. As práticas de leitura descritas pelas professoras foram compreendidas como uma instância de manifestação das representações, e não como uma consequência do sistema simbólico produzido por elas. Afinal, "o comportamento e a ação estão lógica e necessariamente conectadas às crenças representacionais" (Wagner, 1995, p. 178).

$\mathrm{Na}$ pesquisa que empreendemos, ultrapassamos o levantamento de concepções e imagens acerca do objeto em questão - a leitura literária — para compreender o quadro de referências construído pelas professoras, ao organizar o seu discurso e a sua ação docente. Esse foi um processo que demandou discernimento e distanciamento, num movimento de guarda contra as nossas próprias expectativas e necessidades, aos nossos próprios hábitos e representações.

Ao fazer o mapeamento das representações de leitura, foi possível identificar múltiplos olhares sobre a literatura, desde uma abordagem que considera as determinações de ordem pedagógico-moralizantes, até aquelas que concebem o texto como espaço de fruição e experiência estética. Nesse intervalo, foram identificadas outras perspectivas de compreensão - as representações compõem um sistema verdadeiramente estruturado, que revela diferentes significações construídas no transcurso do tempo. Foi possível também perceber que, ao ser proposta uma nova forma de compreender as práticas de leitura literária, os sujeitos não descartaram antigas práticas - elas deixaram a sua marca nos processos que foram se constituindo.

Neste artigo ${ }^{2}$, para melhor compreensão do quadro de referência construído pelas professoras, o conteúdo de suas representações encontra-se organizado em três seções. Na primeira, abordamos os processos de ancoragem e objetivação das categorias prazer e funcionalidade da leitura literária; enquanto, na segunda, discutimos práticas de leitura mediadas pelas professoras junto às crianças. Por fim, na terceira seção são analisadas vivências de leitura das professoras.

2 Artigo produzido a partir de Dissertação de Mestrado em Educação, realizada junto à Faculdade de Educação da Universidade Federal de Minas Gerais (UFMG), revisitada e ressignificada na discussão aqui apresentada. A pesquisa contou com financiamento da Coordenação de Aperfeiçoamento de Pessoal de Ensino Superior (Capes). 


\section{ANCORAGEM E OBJETIVAÇÃO DA LEITURA LITERÁRIA}

As representações sociais se definem como um componente mental do objeto e correspondem a um ato de pensamento com o qual o sujeito se refere a este objeto, sendo importante compreender seu processo de estruturação. "No real, a estrutura de cada representação apresenta-se-nos desdobrada, tem duas faces tão pouco dissociáveis quanto a página da frente e o verso de uma folha de papel: a face figurativa e a face simbólica"(Moscovici,1978, p. 65). Ainda conforme o autor, nessa estrutura, a toda figura corresponde um sentido e a todo sentido uma figura. Pela face figurativa, o sujeito utiliza imagens construídas para tornar concreto e presente o objeto representado; e pela face simbólica, faz-se a correspondência de um sentido a uma imagem, integrando o objeto ao seu universo. O núcleo figurativo é compreendido como uma imagem estrutural que reproduz de forma visível um arcabouço conceptual.

Em nosso estudo, foi importante pensar os mecanismos de estruturação do núcleo figurativo das representações de leitura das professoras. Estruturação que se constituiu como elaborações conceituais e indicou que as professoras se apropriaram de conteúdos em circulação, incorporaram conhecimentos e valores, produziram crenças, fizeram investimentos cognitivos e afetivos, representaram a leitura literária. Em suas elaborações, o objeto livro de literatura foi tomado como imagem em torno da qual se estruturou o núcleo figurativo das representações de leitura. A outra face dessa imagem é a criança leitora, sujeito que não apenas lê os livros, mas gosta de ler e tem a leitura como instrumento de aprendizagem. Tal imagem se construiu pelas vivências de leitura das professoras, como também por sua imersão no cotidiano da sala de aula, que lhes colocou frente ao desafio de alfabetizar e formar leitores. Nesse desafio, as professoras se constituíram como mediadoras entre livros e crianças, visando desenvolver o gosto de ler e influenciar trajetórias de leitura e de vida. É nesse lugar que as professoras entrevistadas se movimentaram e agiram, orientadas pela crença de que ler é um bem, elas produziram estratégias e táticas para realizar práticas de leitura e promover o livro.

Ao pensar a leitura pela lógica das professoras, percebemos que o núcleo figurativo de suas representações se encontra repleto de palavras e sentidos, que definem o que elas pensam e sentem, esperam e praticam, projetam e idealizam. Livro, leitor, leitura, aprendizagem, conhecimento, ludicidade e trabalho são expressões que integram suas elaborações cognitivas, por um movimento em que o prazer de ler se encontra imbricado nas práticas utilitárias de leitura literária, em que o livro é objeto central.

Ao eleger o livro de literatura como elemento constitutivo do núcleo figurativo de suas representações de leitura, as professoras constroem o sentido da leitura como possibilidade lúdica, estabelecendo uma relação da criança com o livro literário como processo orientado pelo prazer. No entanto, no ofício docente, lazer e prazer são valores dissonantes no quadro de referências das professoras. Isso porque, a sala de aula é espaço em que se orientam atividades e aprendizagens, controlam-se tempos e espaços, propõem-se procedimentos de avaliação. Ou seja, a escola é lugar de trabalho e não de lazer, o prazer não é objetivo a ser atingido no processo de ensino. 
E assim, ultrapassando essas dissonâncias, as representações das professoras se expressam por discursos fortemente orientados pelo prazer do leitor e atitudes direcionadas para a funcionalidade da literatura, por um processo em que as características lúdicas do texto literário garantem o encontro da criança com os livros e a abordagem pedagógica da obra promove o aprendizado de conteúdos escolares. Por isso, a leitura literária se apresenta pela lógica do trabalho e não pela gratuidade daquele que lê. E, imbuídas da necessidade de garantir as habilidades de leitura e outros conteúdos escolares, as professoras vêem o prazer de ler como ameaça à sua identidade profissional docente. Prazer não se constitui como objetivo da escola, sendo esta uma perspectiva que incomoda as professoras, que acabam por associar o prazer de ler com perda de tempo. A ameaça e o incômodo são potencializados pelo contexto educacional brasileiro e a realidade da aprendizagem das crianças. Se nos reportamos ao modo como o Brasil se estabeleceu como país, percebemos que este é um processo marcado pela não democratização das oportunidades educacionais e pela não garantia da alfabetização a todas as crianças.

Historicamente, o nosso país colocou em prática um modo restrito ou gradual de difusão da alfabetização, o que transformou o analfabetismo em problema crônico. Estima-se que, em 1820, apenas 0,20\% da população era alfabetizada, índice que sofre progressões gradativas a partir do século XX. Em 1960, o percentual de pessoas alfabetizadas é de $53,3 \%$, sendo este um momento em que, pela primeira vez, ocorre uma inversão da proporção e o número de alfabetizados se apresenta superior ao de analfabetos. Em 2003, o número de analfabetos girava em torno de $17 \%$ (UFMG, 2003). Já no ano de 2015 , era de $8 \%$ a taxa de analfabetismo de pessoas com 15 anos ou mais de idade (IBGE, 2020).

Apesar da redução progressiva no número de analfabetos, as avaliações sistêmicas indicam que a proficiência de leitura dos estudantes brasileiros ainda não atingiu índices recomendáveis. O Programa Internacional de Avaliação de Estudantes (PISA) realizado pela Organização para Cooperação e Desenvolvimento Econômico (OCDE) indica progressos gradativos, mas ainda não satisfatórios, de leitura de alunos brasileiros na faixa etária de 15 anos. Na primeira edição da avaliação, aplicada no ano 2000, o Brasil ficou em último lugar dentre os 32 países que participaram do processo, obtendo apenas 396 pontos nas habilidades de leitura. Nas edições subsequentes, os resultados indicam que o Brasil obteve melhoras, sendo que, na edição de 2018 , em que participaram 80 países, os estudantes brasileiros atingiram 413 pontos, ocupando o $57^{\circ}$ lugar no ranking - posição que ainda revela dificuldades em leitura e compreensão de textos.

O estudo Retratos da Leitura no Brasil, realizado em 2015, por meio de 5.012 entrevistas pessoais e domiciliares, com sujeitos representativos da população brasileira com mais de 5 anos de idade, indica que $57 \%$ dos entrevistados consideram-se leitores, enquanto $43 \%$ afirmam que não o são. "Trata-se de uma pesquisa na qual quem declara ter lido um livro inteiro ou em partes nos três meses anteriores à investigação é considerado LEITOR, sendo considerado NÃO LEITOR quem não leu um livro inteiro ou em partes no mesmo período" (Lajolo, 2016, p. 117, grifos do original). $\mathrm{O}$ estudo encontra-se em sua $4^{\mathrm{a}}$ edição e revela que embora $\mathrm{o}$ número de leitores tenha aumentado, desde o ano de 2007, ainda persiste o desafio 
da formação de leitores e do desenvolvimento de hábitos de leitura. Ao analisar os dados, Lajolo (2016) estranha a ausência da figura do mediador na história de leitura de considerável contingente de leitores - $55 \%$ dos entrevistados dizem que se formaram leitores sozinhos, sem que ninguém os influenciasse em sua prática leitora.

$\mathrm{Na}$ pesquisa, apenas $10 \%$ dos leitores considera que essa figura mediadora seja o professor. Esse é um dado que produz estranhamento e se apresenta ameaçador, sobretudo para profissionais da educação, cujo ofício primeiro é alfabetizar, influenciar leitores e produzir a imersão das crianças no universo da cultura escrita. O estranhamento se amplia ao pensarmos, com Kleiman (1995), que a escola é a principal agência do letramento.

Essa realidade de exclusão de parte da população brasileira de uma aprendizagem que possibilita o acesso aos bens culturais codificados pela escrita, suscita-nos a discutir os processos de ancoragem e objetivação das representações de leitura literária produzidas pelas professoras participantes do nosso estudo. Para superar a ameaça e o estranhamento em relação ao prazer de ler e à gratuidade da literatura, as professoras ancoram a fruição nas práticas utilitárias de leitura — uma possibilidade de tomar o texto literário com a finalidade de educar e ensinar conteúdos escolares. As representações se constituíram por uma forte adesão à literatura, adesão que se mostra perceptível no desejo manifesto pela professora, de "que as escolas passassem a adotar os livros de literatura infantil substituindo os livros didáticos" (P32 $\left.{ }^{3}\right)$.

Conforme Moscovici (1978), as representações sociais têm como uma de suas finalidades tornar familiar algo estranho e ameaçador, isto é, classificar, categorizar e nomear novos acontecimentos e ideias com as quais não se tenha tido contato anteriormente, possibilitando, assim, a compreensão e manipulação desses novos acontecimentos e elementos a partir de ideias, valores e teorias preexistentes e internalizados, já amplamente aceitas pela sociedade. Para trazer o elemento não familiar para o campo familiar são utilizados dois processos dialéticos fundamentais, denominados ancoragem e objetivação.

Ancorar, para Moscovici (2015), significa classificar e dar nome. Isso porque as coisas que não possuem nome são estranhas e ameaçadoras. A ancoragem capta e fixa ideias estranhas, reduzindo-as a categorias e imagens comuns, colocando-as em um contexto familiar para o indivíduo. Por seu lado, o segundo processo de formação das representações sociais, a objetivação, tem a tarefa de externalizar o conhecimento abstraído. Isso significa que, pela objetivação, o sujeito transforma algo abstrato em algo quase concreto, transferindo o que está na mente para algo que exista no mundo físico. Assim, as noções abstratas são transformadas em algo concreto, quase tangível.

Em nosso estudo, as representações das professoras apontam a centralidade do prazer e da fruição estética da linguagem, enquanto a prática apresenta-se marcada pela funcionalidade do texto na educação das crianças. Analisando os discur-

3 Ao citar as falas, as professoras participantes do estudo foram identificadas pela letra $\mathrm{P}$, seguida de um número sequencial (P1, P2, P3 ... P94), visando a preservação de suas identidades. 
sos produzidos e as práticas desenvolvidas, foi possível identificar o conteúdo das representações, construído pela diversidade, mas, também, pelo consenso. Dentre as ideias consensuais, está a tendência unânime em considerar a literatura em sua finalidade educativa, em que as dimensões do prazer e da funcionalidade se entrelaçam na constituição de processos pedagógicos para a escolarização da literatura.

Ao apresentarem 5 adjetivos que melhor qualificam a leitura literária, as 94 professoras participantes do estudo citam 439 expressões adjetivadoras, que integram o núcleo figurativo de suas representações. Destas, 375 (85,42\%) colocam em relevo as práticas de leitura prazerosa e lúdica e indicam a construção da obra literária em sua vitalidade e dinamicidade - características capazes de promover a adesão do leitor ao livro. Tais adjetivações apontam a finalidade fruitiva da literatura, revelam a potência do texto literário em seduzir o leitor, favorecer sua entrada no mundo imaginário e seu envolvimento com a proposta do autor. Um percentual menor de respostas (64 ou 14,58\%) coloca a experiência estética em segundo plano, conferindo atenção aos aspectos que se relacionam à utilização da literatura como instrumento especificamente voltado para finalidades educativas escolares - para o ensino da língua, valores e atitudes socialmente recomendáveis. Esses dados indicam que o universo semântico construído em torno da literatura é, majoritariamente, focalizado na experiência estética e no prazer do leitor.

No entanto, ao apresentarem os critérios orientadores da escolha e indicação de livros para a leitura dos alunos, ocorre uma inversão dessa perspectiva. As 94 professoras participantes do estudo enumeraram 198 critérios, sendo que 115 $(58,08 \%)$ privilegiam a funcionalidade e $83(41,91 \%)$ consideram o prazer na relação leitor-texto. Constatamos que, movidas pelo desejo de formar crianças leitoras, as professoras se apóiam na leitura literária. Mas, para além do prazer de ler, tem-se por expectativa que os alunos acessem os conhecimentos escolares e deles se apropriem. Por isso, as professoras voltam-se para a literatura infantil, apoiando-se em representações consensuais que tomam a leitura como um bem. As professoras fazem coro à ideia naturalizada de que aquele que lê desenvolve competência para compreender os textos lidos, escrever bem, melhorar a ortografia e a pontuação, ampliar o vocabulário e melhorar seus recursos no uso da língua.

Assim, a literatura articulou-se com interesses e competências que a escola considera como seus, tendo presença garantida no espaço escolar, em diferentes formatos disponíveis no mercado editorial que, por interesses mercadológicos múltiplos, responde prontamente às demandas do sistema educacional. Em outras palavras, em seu universo representacional, as professoras ancoram a leitura fruitiva nas práticas de ensino e educação, enquanto a objetivação se dá pelas atividades de dramatização. Dentre as atividades propostas, dramatizar os textos possui grande centralidade, quase uma unanimidade. Das 94 participantes do estudo, 92 (97,87\%) afirmam trabalhar a dramatização de histórias. Apesar de considerar o prazer na realização, foi possível perceber que a proposta de dramatizar não surge como busca da ludicidade do texto. Em sala de aula não se concebe a leitura como atividade desarticulada da aprendizagem.

Por essa lógica, para o aluno, dramatizar é uma forma de interpretar o texto lido, apresentar resultados, tornar visível a leitura realizada. A dramatização 
inseriu-se na prática docente, assumindo função similar àquela desempenhada pelo exercício - uma forma de controlar a atividade do aluno, avaliar desempenhos e mostrar que a escola tem cumprido uma função. Buscando atingir o princípio de ludicidade, dramatizar histórias assumiu um cunho utilitário. Valorizar a criatividade pela encenação de histórias pode parecer uma inovação didática, que se encontra com os ideais renovadores de gosto pela leitura e interesse do aluno. Contudo, essas atividades, quando sustentadas por objetivos pragmáticos, não tomam a leitura como experiência estética.

Para as professoras, dramatizar o texto literário se constituiu como prática familiar, conferindo concretude e materialidade à leitura prazerosa, sendo, ao mesmo tempo, possibilidade de utilizar o texto literário com a finalidade de ensinar e educar. Para a escola - instância alicerçada no trabalho - é estranho promover prazer e entretenimento à criança. Por isso, pela dramatização, as professoras transmutam o estranhamento do prazer em algo familiar.

As professoras assumem posicionamento idealizado ao qualificar a literatura, mas se apresentam realistas ao assumir a função docente e indicar leituras para seus alunos. $\mathrm{Na}$ indicação de critérios de escolha de obras, as respostas produzem um deslocamento do prazer - central nas adjetivações da literatura - para uma concepção que tem a literatura como recurso para o ensino, objeto que atende a finalidades educativas.

\section{O LUGAR DA LITERATURA NA FORMAÇÃO DE CRIANÇAS LEITORAS}

Discutir representações de leitura e o lugar da literatura na formação de crianças leitoras implica investigar as práticas de leitura na vida cotidiana e no interior das práticas mediadas pela escola. Importante demarcar que, no Brasil, influenciados por discussões sobre as práticas de leitura e o poder da escrita, ganham centralidade a alfabetização, os métodos e os materiais para ensinar a ler e escrever. A partir das últimas décadas do século XX, foram pautadas discussões sobre letramento, compreendido por Soares (1999, p. 18) como "resultado da ação de ensinar ou de aprender a ler e escrever: o estado ou a condição que adquire um grupo social ou um indivíduo como consequência de ter-se apropriado da escrita”. Por essa lógica, tornou-se necessária a distinção entre o indivíduo alfabetizado, aquele que sabe ler e escrever, e o indivíduo letrado, aquele que se encontra imerso em práticas sociais, sendo capaz de responder adequadamente às demandas sociais por leitura e escrita.

Na visão de Kleiman (1995), como principal agência do letramento, a escola preocupa-se apenas com um tipo de letramento - aquele que se relaciona com as competências de alfabetização dos alunos. E, ao centrar o foco no processo individual de aquisição do sistema alfabético de escrita, a escola deixa de considerar o seu uso por diferentes grupos sociais e em diferentes situações discursivas. Ao discutir o letramento, considera-se que à leitura podem ser associadas múltiplas finalidades, em que ler pode se constituir em instrumento de sobrevivência e trabalho, como processo de integração e participação social. A leitura pode, ainda, tornar-se fruição estética da linguagem, prática desinteressada, em que o leitor não se orienta por 
finalidades imediatistas, mas busca no livro um espaço de prazer, desenvolvimento de sensibilidade e humanidade.

Esta última perspectiva é aquela que se aproxima da ideia de letramento literário. Cosson (2019) entende que o letramento literário seja processo dinâmico de apropriação da literatura e construção de sentidos. Para o autor, a singularidade da construção literária de sentidos vem da interação verbal única e intensa com um mundo feito de palavras, como também da experiência de mundo que o texto literário concentra e disponibiliza e para a qual não há limites temporais ou espaciais. Nessa direção, Lajolo (2001b, p. 44) entende que

a literatura é porta para variados mundos que nascem das várias leituras que dela se fazem. Os mundos que ela cria não se desfazem na última página do livro, na última frase da canção, na última fala da representação nem na última tela do hipertexto. Permanecem no leitor, incorporados como vivência, marcos da história de leitura de cada um.

O letramento literário apresenta-se como processo capaz de desenvolver nossa sensibilidade e humanidade, ampliar horizontes culturais e desenvolver no leitor o senso crítico em relação ao que vê, ouve e lê. Leitura literária é "o exercício da liberdade que nos torna humanos. É por esta força libertária que a literatura sempre participou das comunidades humanas" (Cosson, 2019, p. 25).

O modo literário de realizar a leitura exige um leitor diferenciado, com capacidade para questionar verdades; leitor que se envolve com o texto, se encanta com o imprevisível e inusitado, que prefere textos transgressores àqueles que apresentam a realidade de forma linear e fechada. E um leitor que constrói este tipo de relação com a literatura "aprende a ler os avessos, descobre a transgressão" (Leite, 1995, p. 53).

Apesar de argumentos vários em defesa da leitura literária, Zilberman afirma ser o livro um objeto "tornado estranho no meio escolar" (Zilberman, 1990, p. 20). Para Lajolo (2001a), a relação entre estudantes, professores e literatura precisa ser discutida, uma vez que:

o desencontro literatura-jovens que explode na escola parece mero sintoma de um desencontro maior, que nós — professores — também vivemos. Os alunos não lêem, nem nós; os alunos escrevem mal e nós também. Mas, ao contrário de nós, os alunos não estão investidos de nada. (Lajolo, 2001a, p. 16)

No espaço das escolas, crianças e jovens ainda não construíram uma relação de prazer com o objeto livro, não desenvolveram habilidades necessárias à produção literária de sentidos, veem a leitura como obrigação. Em nosso estudo, as professoras produziram uma representação em que a literatura é tomada como instrumento capaz de reverter trajetórias e encaminhar uma história escolar bem-sucedida para os alunos. Em seu sistema de significações, as representações são altamente favoráveis à presença da literatura, por considerar sua eficácia na promoção da leitura e na formação de alunos-leitores. Ao falar dos resultados de sua ação pedagógica, as professoras demonstram sua insatisfação — os alunos não gostam de ler, não veem a leitura como atividade envolvente e gostosa, suas práticas e habilidades leitoras 
não apresentam a proficiência desejada. O livro é visto como instrumento redentor, mas o encontro leitor-livro ainda está por se constituir.

Contudo, esse desempenho insatisfatório não é tributado à literatura que, nas representações construídas, é preservada em sua capacidade de promover a leitura e encantar os leitores. Ou seja, ler faz bem, é objetivo a ser perseguido, e a literatura é recurso capaz de ampliar as competências do leitor - se não o faz é porque as condições não favorecem. O contexto é utilizado para ancorar a angústia pelo fracasso da escola em promover a leitura. Mas, na busca de explicações para o desencontro leitor-livro, são preservados elementos que compõem o núcleo figurativo das representações - a literatura é um bem que deve ser parte da vida dos alunos. Nesse processo, são identificadas diferentes causas para o problema da não-leitura, que se localiza na omissão da escola, na escassez de livros, na deficiência das bibliotecas e cantinhos de leitura, na falta de investimentos na formação inicial e no desenvolvimento profissional docente.

São grandes as dificuldades enfrentadas pelos alunos, maiores ainda as angústias das professoras que tomam a literatura para o desenvolvimento de competências leitoras, mas, se sentem impotentes e confusas pelos entraves com os quais se deparam no cotidiano profissional: "Geralmente os alunos que têm o costume de ler são bem desenvolvidos na escola. Eles melhoram na leitura oral e na interpretação" (P1); "Sei que o ato de ler é de fundamental importância, mas o que fazer para que o seu aluno se interesse pela leitura e faça uso da mesma, quando este alega não gostar de ler?” (P42).

Nesse quadro de incerteza, as professoras procuram demarcar posição, fazendo da literatura infantil sua aposta, atribuindo-lhe um status privilegiado: o de instrumento para promover o hábito de leitura, constituir práticas leitoras e, por consequência, produzir a imersão das crianças no mundo da cultura escrita. As angústias e a frustração são ancoradas na literatura, vista como possibilidade para instaurar novas habilidades. Para tornar a prática profissional mais lúdica e interessante, a literatura é eleita como recurso para reverter o desencontro da criança com a leitura. Os discursos revelam uma atitude favorável à inserção da literatura na vida das crianças, mas indicam a urgência de melhorar as condições individuais e escolares:

Eu acho que a literatura é muito importante na vida, principalmente da criança que está em formação, mas a escola não se preocupa com essa questão e está mais ligada à aprendizagem do português e matemática e acaba não dando oportunidade do professor trabalhar mais a literatura em sala de aula. Ou não incentiva o professor no valor que a literatura infantil tem. (P85)

"Hoje trabalho [a literatura] com os meus alunos, pois acho muito importante despertar nos alunos o gosto e o prazer pela leitura. Pois sei que não foi trabalhado em mim na infância esse gosto e isso me fez muita falta"(P64).

No sistema de significação produzido pelas professoras, é consensual considerar a literatura infantil como produção cultural essencial à formação das crianças. Contudo, para que possa servir à educação, a literatura deve possuir qualidades que 
a tornem um tipo especial de texto: "Deve ser envolvente, interessante, conter mensagens positivas, ter enredo interessante etc." (P12); "Leitura que lhe dê prazer, que desperte a sensibilidade, a criatividade, o senso crítico, que lhe traga sentimentos de alegria ou tristezas"(P45); "Os adjetivos que melhor qualificam a leitura literária são aqueles que mexem com a sensibilidade, emoção, prazer e a criatividade e também, levam o leitor a um senso crítico" (P35).

Essa centralidade da literatura se dá não apenas por melhorar as condições de inserção no universo letrado. O texto é considerado recurso capaz de criar possibilidades para outras aprendizagens, para assimilação de conteúdos curriculares, valores morais e éticos, para produzir um posicionamento do leitor frente à realidade mais ampla. Nas representações das professoras: "O ato de ler mereceria por parte da escola atenção especial, pois quando o leitor adquire o hábito de ler é que compreende e entende o mundo em sua volta. Por que não resgatar a prática de leitura em nossos alunos?" (P58); "Sempre trabalho com leitura literária porque a considero importantíssima. Mesmo com pouco material que possa me orientar melhor, os alunos não ficam sem esta participação" (P31).

Para promover a leitura e o gosto pelo livro, a literatura apresentou-se como porto seguro, a ancorar desejos, esperanças e expectativas. No processo de sua elaboração, o núcleo figurativo das representações foi solidamente construído a partir do objeto livro, em suas dimensões de prazer e funcionalidade. Nas representações das professoras, a literatura associou-se a aspectos pragmáticos do ensino, mas, os discursos se orientavam por uma perspectiva lúdica, como forma de promover adesão do seu público, ao mesmo tempo em que poderia oportunizar acesso aos conhecimentos.

A presença do prazer e da funcionalidade nas representações das professoras não implica igualdade de status destas duas dimensões de análise. Em seus discursos, as professoras priorizam a primeira, colocando as questões pragmáticas em segundo plano, porque "a literatura é um saber-prazer e não um fazer-saber"(P35). Se o discurso priorizou a ludicidade, as práticas mediadas revelaram uma inversão de perspectiva - a utilidade da literatura assumiu grande centralidade, em que prazer se torna um mero suporte para leitura. Empenhada em trabalhar conteúdos curriculares, as professoras não encontraram tempo para conciliar as demandas do ensino com a fruição. Para as professoras, "o tempo escolar é curtíssimo para desenvolvermos todo o programa necessário para aprendizagem e lazer dos alunos"(P41).

A escola é agência de letramento, espaço privilegiado para o encontro entre leitores e livros, sendo que o professor está investido da responsabilidade por esta mediação. Para Barthes (1987, p. 43), "existe uma antinomia profunda e irredutível entre a literatura como prática e a literatura como ensino. Esta antinomia é grave porque se liga ao problema que é talvez hoje o mais escaldante, e que é o problema da transmissão do saber". Segundo o autor, as grandes estruturas da alienação econômica já foram desveladas, porém as estruturas da alienação do saber não o foram. Aí reside o que se constitui em problema fundamental para o equacionamento dessa antinomia. Supondo que a literatura pode ser compatível com o ensino, o autor acredita que os processos de sua escolarização precisam ser modificados, sofrer correções para que os professores sejam capazes de manter um discurso, sem 
imposição, "pois o que pode ser opressivo no ensino não é finalmente o saber ou a cultura que ele veicula, são as formas discursivas através das quais ele é proposto (Barthes, 1987, p. 43).

Ainda na opinião de Barthes (1987), são três os pontos de correção imediata a serem atacados no ensino da literatura. $O$ primeiro consiste em inverter o clássico-centrismo para fazer a história da literatura às "arrecuas". Ou seja, romper com a linearidade em que os estudantes se veem obrigados a estudar literatura a partir de uma sequência cronológica, onde os fatos se sucedem, sem relação com a situação presente. $\mathrm{O}$ segundo princípio visa promover a substituição do autor, da escola e do movimento pelo texto. O texto, nas nossas escolas, é tratado como objeto de explicação, quando deveria ser considerado como espaço da linguagem, investido de certo número de códigos de saber. O terceiro princípio pretende conduzir o ensino da literatura, de forma que possa, em cada ocasião e em cada instante, desenvolver uma prática polissêmica de leitura do texto, abrindo-o ao simbolismo.

A construção de um ensino que tenha essas características depende do redimensionamento de práticas, pela superação dos antagonismos presentes nas atividades escolares e nos discursos acadêmicos que, ora privilegiam o pedagógico, ora o estético na abordagem da literatura.

\section{LIVROS E LEITURA NAS REPRESENTAÇÕES DAS PROFESSORAS}

No processo de produção das representações, entram em jogo não apenas as vivências, mas, sobretudo, o discurso que legitima e institui a literatura como prática cultural. Assim, ao analisar os sistemas de significação produzidos, é importante compreender os discursos das professoras em sua interlocução com outros conteúdos veiculados pela sociedade, já que é nesse diálogo que as representações são produzidas.

Compreender esse complexo quadro que compõe as representações de leitura literária nos remeteu para o contexto social em que foram constituídas. "Se a atividade do sujeito é central para a teoria, não menos central é a realidade do mundo" (Guareschi e Jovchelovitch, 1995, p. 19). Dito de outra maneira, as representações sociais são explicadas na interface entre o individual e o social; se constituem como atividade cognitiva e ocorrem em um espaço social, sofrendo interferência dos conteúdos produzidos em diferentes tempos históricos de curto, médio e longo prazos.

A constituição da escola como instituição responsável pela educação formal coloca em relevo o seu papel de favorecer o desenvolvimento social e cultural da criança. Assim, a escola lança mão de estratégias e materiais diversos, sendo a literatura um recurso sempre presente. Segundo Arroyo (1990), desde as origens da literatura infantil e em todos os países em que se tornou realidade, sempre esteve em pauta a preocupação com as relações técnico-pedagógicas que permeiam sua entrada e utilização pela escola. No século XIX, desenvolveu papel relevante em função do atrelamento a objetivos didáticos, também "revelando e preparando, despertando e cultivando o hábito da leitura entre as crianças da época” (Arroyo, 1990, p. 98).

Zilberman (1991) considera que a escola se apóia na necessidade de conhecimento da história da literatura nacional, sua tradição e seus membros ilustres como 
justificativa para a presença da literatura na sala de aula. A literatura serve, ainda, à questão gramatical, como modelo de utilização da língua nacional e às questões de ordem moral, nos casos em que a ficção assume uma orientação pedagógica e passa a veicular valores e regras socialmente aceitos. Lajolo e Zilberman (1984) destacam a forte preocupação perfeccionista com a linguagem, cuja função de modelo é assumida pela literatura produzida para crianças, que, além de fornecer exemplos de qualidades, sentimentos, atitudes e valores, manifesta a correção da linguagem, divulgando uma representação sólida e ufanista do país - conhecimentos que a escola se encarregou de difundir. E assim, o desenvolvimento da literatura no Brasil acompanhou o ritmo da escola, afirmou-se como produção cultural a partir da organização da escola brasileira e teve o seu boom na década de 1970, com a entrada massiva das crianças no sistema de ensino (Soares, 1999).

É, portanto, para atender interesses educativos, que a literatura tem entrado na escola. Para Arroyo (1990), nem sempre foi possível estabelecer separação nítida entre livros de puro entretenimento e os de leitura para aquisição de conhecimentos e estudos. Os livros de literatura infantil propriamente dita tiveram sua origem no livro escolar, no livro útil e funcional, que atendia objetivos didáticos.

No entanto, para além dessa perspectiva pragmática adotada pela escola, Bettelheim (1980), Abramovich (1997), Cosson (2019) e Wolf (2019), dentre outros autores, afirmam que o texto literário favorece o desenvolvimento da nossa humanidade, por nos conectar com o outro, possibilitar acesso à experiência do outro, sentir dor e tristeza ou felicidade e alegria, dentre muitos outros sentimentos, através das narrativas. A capacidade de empatia ou de assumir as perspectivas e os sentimentos do outro é, segundo Wolf (2019), uma das contribuições mais profundas e insuficientemente enunciadas da leitura profunda, da experiência de ler textos literários e transportar-se para diferentes mundos, sem que se tenha afastado um palmo de nossos mundos particulares. "Assumir uma perspectiva não só conecta nossa empatia com o que acabamos de ler, mas também expande nosso conhecimento interiorizado do mundo. São capacidades aprendidas que ajudam a nos tornar mais humanos" (Wolf, 2019, p. 59).

Benjamin (2012) considera que o livro de literatura tem grande potencial formativo, exatamente por trazer à criança a realidade de tipos humanos. Para o autor, "a criança compreende perfeitamente coisas sérias, mesmo as mais abstratas e pesadas, desde que partam honesta e espontaneamente do coração e, por isso, algo pode ser dito a favor daqueles velhos textos" (Benjamin, 2012, p. 265).

Em nosso estudo, constatamos que as professoras se sentem responsáveis por educar as crianças e lhes favorecer acesso a conhecimentos socialmente legitimados. Por essa argumentação, em suas representações, a literatura infantil encontra amplo espaço. O prazer de ler literatura, via pela qual se torna possível o desenvolvimento da sensibilidade, não é compreendido como parte do processo educativo. Educar os sentidos, a percepção, a sensibilidade, favorecer a conexão com o outro e desenvolver a nossa humanidade não se apresentou como objetivo escolar. Para as professoras, o envolvimento do leitor com a literatura foi ancorado em duas formas distintas de compreensão: é estratégia que promove a adesão da criança ao livro e permite realizar a interpretação de textos e outras atividades; ou se associa ao lazer, e por 
isso não encontra espaço nos tempos escolares, nos quais as demandas curriculares se tornam prioritários.

A partir desse raciocínio, é possível compreender o depoimento que se segue, em que a professora torna clara a sua representação - a leitura precisa servir a algum propósito, atingir objetivos curriculares: "Que os educadores acreditem que ler é a melhor solução para os nossos alunos. Lógico que não é ler somente por ler. Mas procurar sempre aprofundar dentro da capacidade dos seus alunos, motivando, criando, recriando, sempre" (P33); "Eu trabalho muito com a emoção e o tempo todo tento resgatar o brilho no olhar do meu aluno, explicando para ele que não é só a capa ou a ilustração que faz o livro, mas a história em si, a sua mensagem" (P62).

Por esta ótica, a leitura pode ser uma atividade desejada, mas não uma experiência gratuita. A leitura, em si, não se constitui em objetivo, precisa estar a serviço de outro propósito. $\mathrm{O}$ prazer encontra-se associado à realização de atividades de ensino. Essas representações se constituíram a partir de conteúdos em circulação, que estabelecem finalidades educativas para a leitura literária e alimentam o universo de referência das professoras. Cosson $(2019$, p. 14) afirma que a presença da literatura na escola se inscreve em uma tradição que remonta aos gregos. "Tal tradição consistia no uso pedagógico da literatura como meio e fim de um processo educativo, no qual, em um primeiro momento, os textos literários serviam de instrumento de acesso ao mundo da escrita, depois passavam a ser objeto de conhecimento" (Cosson, 2019, p. 14). $\mathrm{O}$ autor considera que essa aliança entre escola e literatura era de mútuo benefício. De um lado, a escola cuidou da preservação e transmissão dos textos considerados relevantes, ao mesmo tempo em que formava leitores competentes para o seu consumo. Por outro lado, a literatura tinha a função de fornecer textos funcionais para os leitores aprendizes e textos culturalmente complexos aos leitores já formados (Cosson, 2019).

Para as professoras participantes do nosso estudo, prazer e funcionalidade encontram-se imbricados em uma perspectiva complementar - leitura literária é atividade prazerosa, que serve ao propósito de contribuir para a formação das crianças. Ou seja, não se lê apenas para apreciar o projeto gráfico, a capa e as ilustrações, pois o livro tem um conteúdo e possibilidades educativas implícitas. Por isso pode-se afirmar que, prazer e funcionalidade não são abordagens excludentes. $O$ prazer tem uma função - a de promover o encontro fundamental com o ensino.

Por esta visão, que concebe a literatura como instrumento educativo por excelência, uma intrincada estrutura compõe o quadro das qualidades e características que devem ser contempladas. O texto deve apresentar características que viabilizem "o lúdico, a fantasia, as possibilidades de extrapolação de ideias e opiniões críticas" (P40). Considerando que as dimensões do prazer e da funcionalidade se encontram imbricadas nas representações e nas práticas das professoras, o(s) livro(s) mais indicado(s) é(são) aquele(s): "Adequado à realidade do aluno para facilitar a compreensão" (P05); "Que desperte o interesse, a criatividade dos alunos, levando-os a serem participativos e críticos, que dê margem à leitura de mundo"(P20); "Que tenha um bom enredo e que desperte o interesse dos alunos" (P84); "Livro que poderá ser trabalhado de forma interdisciplinar com algum assunto em questão. Enredo agradável" (P01); "Que explorem os conceitos atitudinais. Propiciar momentos de 
prazer ao ouvir e ler uma história" (P09); "Que tragam mensagens boas e possam ser aproveitados pelos alunos. Que despertem o senso crítico. Livros que sejam envolventes e que possibilitem as crianças uma viagem pela história lida” (P12).

Nas representações das professoras, o livro deve envolver os alunos, propiciar momentos de prazer, mas, também, adequar-se à realidade, criar condições para formação de conceitos e atitudes, suscitar processo reflexivo e promover a inserção crítica e criativa no mundo. A leitura se encontra marcada por múltiplos interesses, gerados pelo desejo e o envolvimento do leitor com a obra, sem perder de vista os conteúdos curriculares e valores socialmente legitimados. Sem o prazer não é possível atingir os objetivos de apropriação dos conteúdos.

Para as professoras, é inegável a importância da literatura no processo de formação das crianças. Em suas representações, as dimensões do prazer e da funcionalidade engendram-se na constituição de uma atitude favorável à presença do texto literário. Ao falar sobre as modalidades de textos com os quais mais gostam de trabalhar com seus alunos, as professoras apresentaram argumentos que apontam para a literatura e a leitura-prazer. Contudo, os textos também precisam possibilitar a aprendizagem, e essa possibilidade de trabalho é uma característica dos textos informativos:

Acho que devem ser trabalhados mais textos informativos nas escolas, pois os livros infantis são bons (parte deles), mas muitas vezes uma notícia de jornal, uma reportagem de revista, uma receita pode ser de muito mais significado para $\mathrm{o}$ aluno, mesmo das séries iniciais, como no meu caso que trabalho com $2^{\circ}$ ano básico, os meus alunos adoram reportagens (é claro tenho cuidado com estas reportagens). (P53.)

Uma professora apresenta o seu temor em relação aos "exageros" de uma literatura que promova o distanciamento da realidade. Ao falar dos critérios que utiliza para escolher e indicar livros, afirma: "O terceiro critério é se a história apresentada no livro possa levar o meu aluno a despertar sua sensibilidade e o gosto pela leitura sem exageros demasiados que fujam completamente da realidade" (P76).

Os posicionamentos das professoras nos permitem perceber a presença de diferentes elementos, que se encontram imbricados, conferindo um sentido para a realidade social vivida pelos sujeitos e para as demandas impostas pela sala de aula. Apesar de, em suas práticas, estar implícita a dimensão funcional, em seus discursos, as professoras afirmam a centralidade da dimensão prazer.

\section{CONSIDERAÇÕES FINAIS}

As representações de leitura literária não são a tradução de práticas efetivamente vivenciadas, mas a forma como as professoras apreendem essa realidade e lhe conferem significados. As práticas integram as representações, que também se expressam por meio de crenças, expectativas, opiniões e imagens construídas no decurso de suas trajetórias de vida.

Por encontrar-se associada à função de reapresentar, as Representações Sociais podem trazer à consciência algo que está ausente, podendo estar premidas de 
sentidos outros não explicitados no discurso, mas construídos durante a trajetória dos sujeitos. Ao falar sobre a leitura, as professoras imprimiram sua compreensão acerca do fenômeno e projetaram expectativas, apresentando uma relação idealizada com o livro, em que estão delineados suas concepções e os valores socialmente legitimados. Contudo, ao falarem de suas práticas e das intervenções didáticas em sala de aula, tornou-se possível perceber outra dimensão presente em seu universo de significação, que associa o livro a finalidades práticas, voltadas para o ensino de conhecimentos formalmente exigidos pelo sistema educacional.

As Representações Sociais dizem respeito à cognição, aos sentimentos, aos afetos e às emoções, assim como às relações sociais engendradas pelas professoras, às suas vivências como leitoras e mediadoras de práticas escolares de leitura, aos conteúdos sociais que circulam e alimentam a sua produção. É na articulação de ideias, concepções, crenças e utopias que se constituem as representações de leitura literária, objeto historicamente construído e socialmente valorizado. Os significados produzidos configuram uma complexa interação social, que denominamos de Representações Sociais de leitura literária das professoras da rede municipal de ensino de Montes Claros que, em sua totalidade, orientam ações e contribuem, de forma positiva ou negativa, para a adesão da criança ao livro.

Consideramos que, tanto as práticas de leitura mediadas, quanto as causas que as professoras selecionam para explicar o fenômeno da leitura, ou da não-leitura, são orientadas por seu sistema de significações. Ao estudar essas representações, tornou-se fundamental considerar as práticas nas quais se inseriram, os conteúdos em circulação acerca da leitura literária, mas, sobretudo, a atividade de apropriação e interpretação realizada pelas professoras.

As representações das professoras apresentam-se associadas a ideias e interesses pré-existentes, refletindo os diferentes enfoques que os meios educacionais têm conferido à literatura. Quando a escola promove mudanças em sua ação educativa, a literatura também assume contornos diferenciados. É assim que, nas representações das professoras, uma grande variedade de crenças, valores, expectativas e práticas fizeram-se presentes. Contudo, preservam, como núcleo central, a ideia de que a literatura é um bem, educa e deve ser disseminada por processos lúdicos de interação do leitor com o texto. Para as professoras, práticas leitoras precisam ser instauradas, sob pena de a escola ser acusada de se descuidar de algo tão caro à modernidade - a formação de leitores.

Por esta via de compreensão, identificamos posturas idealistas, que promovem a adesão das professoras aos conteúdos veiculados e legitimados socialmente, como, também, posturas realistas, formas pelas quais o idealizado se materializa em práticas possíveis. E, assim, dadas as demandas e cobranças impostas e a natureza da função docente, que impõe o ensino, o trabalho, a avaliação e o controle, as professoras propõem atividades diversas visando às aprendizagens das crianças.

Em outras palavras, as professoras acreditam na fruição da literatura, tomada como elo fundamental entre a criança e esse objeto cultural, prazer capaz de promover a sua adesão e o seu acesso ao conhecimento. Ao assumirem o discurso da gratuidade na relação leitor-livro, as professoras legitimam a sua posição e a presença da literatura na escola; porém, em função das urgências impostas pelo cotidiano, 
essa relação não se constrói facilmente. No lugar onde se prega o desejo e a experiência estética do leitor, são produzidos processos de mediação que privilegiam a funcionalidade da literatura, as possibilidades de sua utilização para o ensino de conteúdos curriculares, atitudes e valores.

O discurso que prioriza o estético, ao se materializar em processos de mediação leitor-livro, assume novos contornos, havendo inversão na perspectiva de compreensão do papel social da literatura. $\mathrm{Na}$ sala de aula, as práticas de leitura firmam compromisso prioritário com a pedagogia e não com a arte.

\section{REFERÊNCIAS}

ABRAMOVICH, F.Literatura infantil: gostosuras e bobices. São Paulo: Scipione, 1997. ARROYO, L. Literatura infantil brasileira. 10. ed. São Paulo: Melhoramentos, 1990. BARTHES, R. Aula. Tradução: Leila Perrone-Moises. São Paulo: Cultrix, 1987. BECKER, H. S. Métodos de pesquisa em ciências sociais. São Paulo: Hucitec, 1993. BENJAMIN, W. Magia e técnica, arte e política: ensaios sobre literatura e história da cultura. Tradução: Sergio Paulo Rouanet. 8. ed. São Paulo: Brasiliense, 2012. v. 1. (Obras Escolhidas).

BETTELHEIM, B. A psicanálise dos contos de fadas. Tradução de Arlene Caetano. Rio de Janeiro: Paz e Terra, 1980.

BOGDAN, R. C.; BIKLEN, S. K. Investigação qualitativa em educação: uma introdução à teoria e aos métodos. Lisboa: Porto, 1994.

COSSON, R. Círculos de leitura e letramento literário. São Paulo: Contexto, 2019. DANIEL, F. D.; ANTUNES, A.; AMARAL, I. Representações sociais da velhice. Análise Psicológica, Lisboa, v. 3, n. 33, p. 291-301, 2015. Disponível em: http://www. scielo.mec.pt/scielo.php?script=sci_arttext\&pid=S0870-82312015000300004. Acesso em: 20 abr. 2020. https://doi.org/10.14417/ap.972

DUVEEN, G. As crianças enquanto atores sociais: as Representações Sociais em desenvolvimento. In: GUARESCHI, P.; JOVCHELOVITCH, S. (org.). Textos em Representações Sociais. 5. ed. Petrópolis: Vozes, 1995. p. 261-293.

GUARESCHI, P.; JOVCHELOVITCH, S. Introdução. In: GUARESCHI, P.; JOVCHELOVITCH, S. (org.). Textos em Representações Sociais. 5. ed. Petrópolis: Vozes, 1995. p. 17-25.

INSTITUTO BRASILEIRO DE GEOGRAFIA E ESTATÍSTICA (IBGE). Diretoria de Pesquisas, Coordenação de Trabalho e Rendimento. Brasil em síntese. Pesquisa Nacional por Amostras de Domicílios 2007/2015. Brasil: IBGE, 2020. Disponível em: https://brasilemsintese.ibge.gov.br/educacao/taxa-de-analfabetismodas-pessoas-de-15-anos-ou-mais.html. Acesso em: 12 abr. 2020.

KLEIMAN, Â. B. Modelos de letramento e as práticas de alfabetização na escola. In: KLEIMAN, Â. B. Os significados do letramento: uma nova perspectiva sobre a prática social da escrita. São Paulo: Mercado de Letras, 1995. p. 15-61. 
LAJOLO, M. Do mundo da leitura para a leitura do mundo. 6. ed. São Paulo: Ática, 2001a.

LAJOLO, M. Literatura: leitores e leitura. São Paulo: Moderna, 2001b.

LAJOLO, M. Números e letras no mundo dos livros. In: FAILLA, Z. (org.). Retratos da leitura no Brasil. Rio de Janeiro: Sextante, 2016.296 p. p. 113-126. Disponível em: http://www.escritoriodolivro.com.br/bibliografia/Retratos\%20da\%20Leitura\%20no\%20 Brasil\%204.pdf. Acesso em: 2 abr. 2020.

LAJOLO, M.; ZILBERMAN, R. Literatura infantil brasileira: história \& histórias. São Paulo: Ática, 1984.

LEITE, L. C.M. Comentário do "texto gerador de Magda Becker Soares". In: ABREU, M. (org.). Leituras no Brasil: antologia comemorativa do $10^{\circ}$ COLE. Campinas: Mercado de Letras, 1995. p. 51-56.

MARKOVÁ, I. A fabricação da teoria de representações sociais. Tradução de Beatriz Gama Rodrigues e João Kaio Barros. Cadernos de Pesquisa, v. 47, n. 163, p. 358375, jan./mar. 2017. Disponível em: http://www.scielo.br/scielo.php?script=sci_ abstract\&pid=S0100-15742017000100358\&lng=es\&nrm=iso\&tlng=pt. Acesso em: 20 abr. 2020. https://doi.org/10.1590/198053143760

MINAYO, M. C. S. O conceito de Representações Sociais dentro da sociologia clássica. In: GUARESCHI, P.; JOVCHELOVITCH, S. (org.). Textos em Representações Sociais. 5. ed. Petrópolis: Vozes, 1995. p. 89-111.

MOSCOVICI, S. A representação social da psicanálise. Rio de Janeiro: Zahar, 1978. MOSCOVICI, S. Representações sociais: investigações em psicologia social. Editado em inglês por Gerard Duveen. Tradução do inglês de Pedrinho A. Guareschi. 11. ed. Petrópolis: Vozes, 2015.

SOARES, M. A escolarização da literatura infantil e juvenil. In: EVANGELISTA, A. A.M. et al. (org.).A escolarização da leitura literária: $O$ jogo do livro infantil e juvenil. Belo Horizonte: Autêntica, 1999. p. 17-48.

UNIVERSIDADE FEDERAL DE MINAS GERAIS (UFMG). Centro de Alfabetização, Leitura e Escrita (CEALE). Faculdade de Educação. Ciclo Inicial de Alfabetização. Belo Horizonte: Secretaria de Estado da Educação de Minas Gerais, 2003.26 p. (Orientações para a Organização do Ciclo Inicial de Alfabetização, v. 1).

WAGNER, W. Descrição, explicação e método na pesquisa das Representações Sociais. In: GUARESCHI, P.; JOVCHELOVITCH, S. (org.). Textos em Representações Sociais. 5. ed. Petrópolis: Vozes, 1995. p. 149-186.

WOLF, M. O cérebro no mundo digital: os desafios da leitura na nossa era. Tradução de Rodolfo Iari e Mayumi Ilari. São Paulo: Contexto, 2019.

ZILBERMAN, R. Sim, a literatura educa. In: ZILBERMAN, R.; SILVA, E. T. (org.). Literatura e pedagogia: ponto \& contraponto. Porto Alegre: Mercado Aberto, 1990. p. 17-24.

ZILBERMAN, R.A leitura e o ensino da literatura. 2. ed. São Paulo: Contexto, 1991. 


\section{SOBRE AS AUTORAS}

Geisa Magela Veloso é doutora em educação pela Universidade Federal de Minas Gerais (UFMG). Professora da Universidade Estadual de Montes Claros (Unimontes).

E-mail:velosogeisa@gmail.com

Aparecida Paiva é doutora em literatura comparada pela Universidade Federal de Minas Gerais (UFMG). Professora da mesma instituição. E-mail: paiva.aparecida@gmail.com

Conflitos de interesse: Os autores declaram que não possuem nenhum interesse comercial ou associativo que represente conflito de interesses em relação ao manuscrito.

Financiamento: $\mathrm{O}$ estudo recebeu financiamento da Coordenação de Aperfeiçoamento de Pessoal de Nível Superior (CAPES).

Contribuições dos autores: Análise Formal, Conceituação, Metodologia, Paiva, A.; Veloso, G.M. Supervisão, Validação, Visualização: Paiva, A. Administração do Projeto, Investigação, Curadoria de Dados, Escrita — Primeira Redação, Escrita — Revisão e Edição, Obtenção de Financiamento: Veloso, G. M.

Recebido em 26 de maio de 2020

Aprovado em 18 de agosto de 2020 